\title{
The balance of power in closely held corporations
}

\author{
Bennedsen, Morten; Wolfenzon, Daniel
}

Document Version

Final published version

Publication date:

1999

\section{License \\ CC BY-NC-ND}

Citation for published version (APA):

Bennedsen, M., \& Wolfenzon, D. (1999). The balance of power in closely held corporations.

Link to publication in CBS Research Portal

\section{General rights}

Copyright and moral rights for the publications made accessible in the public portal are retained by the authors and/or other copyright owners and it is a condition of accessing publications that users recognise and abide by the legal requirements associated with these rights.

\section{Take down policy}

If you believe that this document breaches copyright please contact us (research.lib@cbs.dk) providing details, and we will remove access to the work immediately and investigate your claim. 


\title{
Institut for Nationaløkonomi
}

Handelshøjskolen i København

Working paper 10-99

\section{THE BALANCE OF POWER IN CLOSELY HELD CORPORATIONS}

\author{
Morten Bennedsen \\ Daniel Wolfenzon
}

Department of Economics - Copenhagen Business School

Solbjerg Plads 3, DK-2000 Frederiksberg 


\title{
The Balance of Power in Closely Held Corporations $^{\dagger}$
}

\author{
Morten Bennedsen* \& Daniel Wolfenzon.**
}

\begin{abstract}
We analyze a closely held corporation characterized by the absence of a resale market for shares and by potentially having several significant shareholders. The founder of the firm may optimally choose to distribute voting power to several large shareholders since this forces them to form coalitions to obtain control. A coalition, by grouping the cash flows of its members, internalizes to a larger extent the consequences of its actions and hence takes more efficient actions than its individual members. The model has other implications for the ownership structure of a closely held corporation: A one-share-one-vote rule improves efficiency; the optimal ownership structure has either one dominant shareholder or several equal-sized shareholders; and, finally, efficiency decreases with the number of significant shareholders.
\end{abstract}

JEL Classification: G32, G34.

KEYwORDs: Closely held corporations, ownership structure, control dilution, controlling coalition, one share - one vote.

\footnotetext{
${ }^{\dagger}$ We are grateful to Oliver Hart, Fausto Panunzi, Andrei Shleifer, the participants of the Organization Lunch at Harvard University and an anonymous referee for useful suggestions and comments.

${ }^{*}$ Copenhagen Business School, Centre for Industrial Economics and Centre for Labour Market and Social Research. Institute of Economics, Solbjerg Plads 3, 2000 Copenhagen F, Denmark. Email: MB@CBs.DK, WEB: http://www.cbs.dk/departments/econ/staff/mbennedsen/morten.htm.

**Harvard University. Department of Economics, Littauer Centre, Harvard University, Cambridge, MA 02138. Email: DWOLFEnZ@KUZNETS.FAS.HARVARD.EDU.
} 


\section{Introduction}

We analyze closely held corporations characterized by the absence of a resale market for shares and by potentially having several significant shareholders. Closely held corporations are the dominant form of ownership in developing and transitional economies, as well as in most West European economies. Even in the US, out of 3.6 million corporations, 8,500 only were publicly held in 1989 (US Bureau of the Census (1993) cited in Choper, Coffee and Gilson (1995)).

The corporate governance literature has generally focused on firms with either dispersed ownership structure (Berle and Means (1932) and Grossman and Hart (1980)) or a single controlling shareholder (Jensen and Meckling (1976), Shleifer and Vishny (1986) and Burkart, Gromb and Panunzi (1997)). In the former case, shareholders are too small and disorganized to impose their will and, as a result, control resides in the hands of the manager. In the latter, the dominant shareholder dictates corporate policy either by managing the firm directly, or by closely monitoring the managing team. The remaining shareholders lack either the power or the incentives to oppose the controlling shareholder's decisions.

In the present paper we focus on firms where shareholders are sufficiently large not to surrender control to the manager even though none of the shareholders are able to control the firm alone. ${ }^{1}$ In these firms corporate policy is the result of the interaction among the several large shareholders.

We argue that the purpose of having multiple large shareholders is to prevent a single shareholder from taking unilateral actions that might hurt other shareholders, such as diverting funds from the firm. If a diversion decision is to be taken, it will require the consent of a coalition of shareholders. Since a coalition of shareholders diverts less than any of its individual members, the initial owner seeks the participation of other large shareholders in order to

\footnotetext{
${ }^{1}$ Gomes and Novaes (1999) find that $86.9 \%$ of the closely held corporations in the National Survey of Small Business Finances (NSSBF) with annual sales above 10 mill. USD have at least one large shareholder and $57.2 \%$ have more than one large shareholder.
} 
dilute her power and consequently commit to forming a controlling coalition.

In our model, a firm's initial owner, in need of external capital, sells votes and cash flows to wealth constrained outside investors. Once the ownership structure is determined, there is a control contest among competing coalitions to seize control of the firm. Control is valued by shareholders because it allows them to enjoy private benefits. We assume that these benefits come at the expense of non-controlling shareholders and, moreover, that they are inefficient to extract. The outcome of the control contest is influenced by the ownership structure, i.e., by number of votes and cash flows that each shareholder has. Therefore, when deciding the ownership structure, the initial owner takes into account not only the need to raise funds, but also the way in which the ownership structure will influence the control contest.

Our results about ownership are driven by two opposing effects which we call the alignment and the coalition formation effect. The alignment effect is the positive relation that exists between the cash flow stake of the controlling coalition and total firm value. The more cash flows the controlling coalition possesses, the more it internalizes the costs of its actions, and hence, the fewer costly private benefits it extracts. This effect is similar to that in Jensen and Meckling (1976).

The second and novel effect arises from shareholder equilibrium behavior at the time of coalition formation. Once votes and cash flows are distributed, many different coalitions have sufficient voting power to control the firm. However, out of these coalitions, the one with the smallest cash flow stake wins the control contest. This is because it has the largest group of shareholders (in term of cash flows) to expropriate from. This implies that, conditional on having sufficient voting power to control the firm, this coalition formation effect tends to minimize the cash flow stake of the winning coalition.

With these two effects, we can explain the choice between retaining absolute control and diluting control. Note that the initial owner bears, through the price of the securities she sells, any inefficiency caused by diversion. If the 
initial owner has enough wealth to finance the firm and retain a very large portion of the cash flows, say $80 \%$, then it is optimal for her to retain control. By doing so, the winning coalition, which will contain only the initial owner, will have a considerable fraction of the cash flows. However, if the initial owner's wealth only allows her to retain a smaller fraction, say $55 \%$, then retaining control is not optimal. Consider an alternative ownership structure in which the initial owner sells $33 \frac{1}{3} \%$ of cash flows and votes to each of two investors. With this ownership structure, a coalition of two shareholders will form to control the firm. The controlling body will have $66 \frac{2}{3} \%$ of the cash flows, and will take more efficient action than a controlling body with only $55 \%$. Clearly, the initial owner would like that the coalition that control the firm include all three shareholders (the alignment effect) but, once votes and cash flows are distributed, shareholders incentives are to form a controlling coalition that expropriates the largest set of shareholders (the coalition formation effect) and, consequently, one shareholder is left out.

Not all ways to dilute power generate the same value for the firm. Indeed, most of the analysis will be devoted to understanding the optimal ownership structure when more than one significant shareholder is present. First, we define the concept of control structure as the collection of coalitions with sufficient power to control the firm and find that, for any possible control structure, there is a one-share-one-vote ownership structure that maximizes efficiency. The intuition is that deviations from one-share-one-vote create shareholders with a high vote to cash flow ratio, and the coalition formation effect tends to include these shareholders in the controlling coalition. As a result, this coalition ends up with a small cash flow stake, which is detrimental to efficiency.

Following the initial contributions from Grossman and Hart (1988) and Harris and Raviv (1988), an extensive literature on the optimality of oneshare-one-vote has developed. The novel feature of our result is that it is not derived in the context of takeovers. Thus, our model is better suited to explain the fact that deviations from the one-share-one-vote rule are small in 
most countries, and not only in those with active markets for corporate control (La Porta et al. (1999)).

Second, we establish the relationship between efficiency and the number of shareholders. In particular, we show that as the number of shareholders is increased, efficiency must decline. Third, we show that the best ownership structure is either one where there is a single large shareholder, or one where shareholders are roughly of the same size. The intuition for these two results is similar: As cash flows are distributed among more shareholders or as they are distributed more unevenly, it will be easier to find a coalition with sufficient voting power and a relatively small cash flow stake. Although for different reasons, this last result is similar to a result found in Zwiebel (1995), where the ownership structure is determined by the investors who allocate their wealth across firms in order to receive a larger share of the private benefits.

In our analysis enforceable contracts among the owners can improve efficiency. In many closely held corporations contracts over compositions of the board, voting rules, and veto rights, are used. Moreover, legal scholars strongly advise practitioners to write such contracts (O'Neal (1990)). Unfortunately, these contracts are not always enforced. In the U.S., until recently contracts that altered the statutory system of governance in a corporation were not generally accepted by courts. Our results about the optimal ownership structure would still be valid, even in the presence of such contracts, as long as there is some positive probability that a coalition of shareholders will find a way to 'legally breach' the agreement. We discuss these issues further in Section 6 .

Shleifer and Vishny (1997) argue that, in most countries, the relevant agency problem that corporate governance should address is that of the controlling shareholder expropriating the minority shareholders rather than that of the manager expropriating all shareholders. Consequently, a number of papers (including the current one) suggest that the presence of large shareholders is a mechanism used to mitigate such expropriation. La Porta et al. (1999) and Pagano and Roel (1998) argue that other large shareholders re- 
duce diversion by monitoring the controlling shareholder. Gomes and Novaes (1999) focus on how ex-post bargaining problems among large shareholders may protect minority shareholders in a model that ignores the strategic aspects of coalition formation. Their analysis complement ours, since we focus on the formation process of the controlling coalition and assume away ex-post bargaining problems among its members.

Finally, our result that control dilution is an effective mechanism to reduce diversion when there is the possibility of diversion is diametrically opposed to that of La Porta et al. (1999) and Bebchuck (1999). These papers argue that in countries with poor investor protection control should be concentrated because otherwise someone could seize it without fully paying for it. In our model of a closely held corporation, this cannot happen since once the initial owner sells the securities there is no market for them. In addition, the initial owner receives full payment for the benefits of control that buyers expect to get and therefore is not worried about loosing control but rather about the total value of the firm.

The rest of the paper is organized as follows. Section 2 lays out the model. In Section 3 we analyze the coalition formation process. In Section 4 we fix the control structure (i.e., the voting distribution) and show the optimality of one-share-one-vote. In Section 5 we completely solve for the optimal ownership structure (i.e., both the control structure and the cash flow distribution). Section 6 provides support for our analysis in the legal literature on closely held corporations and in the illustrative Levy versus Markal Sales Corporation case. Finally, Section 7 concludes.

\section{The Model}

The timing of the model is shown in Figure 1. At date 0, an entrepreneur has the opportunity of setting up a firm at a cost $K<1$. We assume that the entrepreneur's wealth is not sufficient to cover the entire set up cost, so she is 


$$
t=0 \quad t=1 \quad t=2
$$

$\begin{array}{lll}\longrightarrow & & \\ \text { Firm established } & \text { Shareholder meeting with } & \text { Winning board diverts } \\ \text { at cost } K . & \text { board selection: } & d \text { and pays } 1-d \\ \text { Entrepreneur sells } & \text { every shareholder } & \text { in dividends. } \\ \text { votes and cash flows. } & \text { announces a coalition } & \\ & C \subseteq I .\end{array}$

Figure 1: time line.

bound to obtain outside finance.

There is a large pool of potential investor which abusing notation we denote by $N=\{1,2, \ldots, N\}$. Each investor has a fix level of wealth, $W_{i}, i \in N$. We refer to each investor by his number or index, and order them such that $W_{1} \geq W_{2} \geq \cdots \geq W_{N}$. We assign the number 0 to the entrepreneur and denote by $W_{0}$ her initial wealth. The entrepreneur chooses a subset of these investors to become shareholders of the firm and sells to each one of them a (potentially different) number of votes and cash flow rights. The entrepreneur might decide to sell out or stay as a shareholder.

The final ownership structure is then described by a set of shareholders $I$ (with $I-\{0\} \subset N$ ) and a number of votes, $v_{i}$, and a fraction of the firm's cash flow, $c_{i}$, for each shareholder $i \in I$. We define $\mathbf{v}=\left\{v_{i}\right\}_{i \in I}$ and $\mathbf{c}=\left\{c_{i}\right\}_{i \in I}$ as the profile of votes and cash flow rights.

At date 1 there is a shareholder meeting that elects the board of the firm. Each shareholder votes for one of the potential boards. Not to rule out any potential board, we assume that all coalitions $C \subseteq I$ are candidates. The winning coalition is the one that receives the most votes, where the number of votes that a coalition $C \subseteq I$ receives is computed by the summing the votes of the shareholders that voted for $C$. In the case of a tied vote, the coalition supported by the shareholder with the lowest number wins. For instance, if the entrepreneur remains as a shareholder and there is a 50-50 
tie, the coalition supported by the entrepreneur wins. This might reflect the power the entrepreneur has as the founder of the firm. In any event, it does not matter who the tiebreaker is and we simply apply this tie-breaking assumption to simplify the voting game. ${ }^{2}$

At date 2 the board in place diverts $d$ of the revenue and pays out the remaining portion in dividends. We assume that funds are lost when diversion is carried out. The cost of diversion is embodied in the diversion technology $B(\cdot)$. For a level of diversion $d$, the diverted amount received by the board is only $B(d)$, which satisfies:

$$
B(0)=0, B^{\prime}(0)=1, B^{\prime}(1)=0, \text { and } B^{\prime \prime}(\cdot)<0 .
$$

The diversion technology corresponds in essence to Jensen and Meckling's (1976) idea of extraction of non-pecuniary benefits. The same set of assumptions for the diversion technology can be found in Burkart et al. (1998).

We assume that the diverted amount is distributed among board members in proportion to the amount of cash flow rights they own. The reason for this ad-hoc assumption is that we want to focus on the conflict between board members and minority shareholders and not on conflicts among board members. With the specific sharing rule that we use members of any potential board unanimously agree on the level of diversion (see comments after Lemma 1 below). In addition, other reasonable sharing rules such as "per head" or "proportional to votes" do not guarantee existence of equilibrium in the voting game for all possible ownership structures. ${ }^{3}$

Letting $d(C, \mathbf{c}, \mathbf{v})$ be the level of diversion that coalition $C$ undertakes when the profile of cash flow rights and votes is given by $\mathbf{c}$ and $\mathbf{v}$, the payoff to each

\footnotetext{
${ }^{2}$ Ties are handled differently in practice. For instance, in U.S. when there is a tie or a 'deadlock', a shareholder can ask a court for 'involuntary dissolution' of the corporation or a judge can impose a buy-out at a judicially determined price (Hamilton, 1996).

${ }^{3}$ Also, there are other plausible games with weaker assumptions that select the same winning coalition. In Bennedsen and Wolfenzon (1999) we model a situation in which a manager has to 'bribe' shareholders in order to be allowed to divert. The coalition the manager chooses to bribe is the same as the winning coalition in this model.
} 
shareholder is:

$$
\pi_{i}(C, \mathbf{c}, \mathbf{v})= \begin{cases}c_{i}(1-d(C, \mathbf{c}, \mathbf{v}))+\frac{c_{i}}{\sum_{i \in C} c_{i}} B(d(C, \mathbf{c}, \mathbf{v})) & \text { if } i \in C \\ c_{i}(1-d(C, \mathbf{c}, \mathbf{v})) & \text { otherwise. }\end{cases}
$$

Letting $P_{i}$ be the price that investor $i$ pays, the entrepreneur solves the following problem at date 0 :

$$
\max _{I \subset N \cup\{0\},\left\{c_{i}, v_{i}\right\}_{i \in I},\left\{P_{i}\right\}_{i \in I-\{0\}}} \pi_{0}(C, \mathbf{c}, \mathbf{v})+\sum_{i \in I-\{0\}} P_{i}-K
$$

subject to $C$ is the winning coalition of the voting game,

$$
\begin{aligned}
& W_{0}+\sum_{i \in I-\{0\}} P_{i} \geq K, \\
& P_{i} \leq \min \left\{W_{i}, \pi_{i}(C, \mathbf{c}, \mathbf{v})\right\} \quad \forall i \in I-\{0\} .
\end{aligned}
$$

The entrepreneur chooses the set of shareholders of the firm from the set of outside investors $N$ plus herself. This set, I, may or may not include the entrepreneur. She also chooses the number of cash flow rights and votes for each shareholder and the amount each outside investor pays. Clearly, when choosing the ownership structure, the entrepreneur considers the effect this structure will have on the control contest (first constraint). The entrepreneur also needs to raise enough funds to pay the set up cost (second constraint). The final constraint, captures two restrictions on $P_{i}$ : An outside investor cannot pay more than his wealth and, under the assumption of a zero interest rate, each outside investor participates only if, at least, he breaks even.

Clearly, the last constraint must be binding for all outside investors since the entrepreneur charges the maximum possible. That is, either $P_{i}=\pi_{i}$ when $\pi_{i} \leq W_{i}$ or $P_{i}=W_{i}$ when $\pi_{i}>W_{i}$. In the latter case, however, the entrepreneur would be loosing some rents to one of the investors (since $\left.P_{i}<\pi_{i}\right)$. Clearly, she tries to avoid this case if possible. Indeed, it is easy to show that, if there is at least one ownership distribution with which the entrepreneur can finance the firm without giving out rents then at the solution we will have $P_{i}=\pi_{i}$. If the entrepreneur is wealthy enough, or there are a few relatively wealthy outside investors, this will indeed be the case.

In general then we will have that $P_{i}=\pi_{i}$ which implies that the entrepreneur receives the entire value that the firm generates. In such a case, 
her objective would be to maximize the value of the firm subject to $\pi_{i} \leq$ $W_{i}$ for all $i \in I-\{0\}$. This is the objective function we have in mind in Sections 4 and 5 .

\section{Characterization of the equilibrium}

In this section we analyze the subgame that starts at date 1 . We take as given the ownership distribution, that is, the set of shareholders $I$ and the cash flow and vote profiles, $\mathbf{c}$ and $\mathbf{v}$. We are interested in two aspects of the equilibrium: the identity of the winning coalition and the amount of diversion that it carries out. The answer to this last question is given in the following lemma.

Lemma 1. Suppose that coalition $C$ is the board and that $\mathbf{c}$ and $\mathbf{v}$ are the cash flow and vote profile. The level of diversion $d(C, \mathbf{c}, \mathbf{v})$ satisfies:

$$
B^{\prime}(d(C, \mathbf{c}, \mathbf{v}))=\sum_{i \in C} c_{i}
$$

In addition the level of diversion is decreasing in the cash flow stake of the winning coalition.

The proof, which because of its simplicity we omit, proceeds by showing that equation (3) is the first order condition of the maximization problem of every member of the board. Hence, they unanimously agree to divert $d(C, \mathbf{c}, \mathbf{v})$. Furthermore, since $B^{\prime \prime}(\cdot)<0$, equation (3) implies that diversion decreases with the cash flow stake of the winning coalition. This is the alignment effect we discussed in the Introduction: The winning coalition internalizes to a larger extent the consequences of its actions and hence engages in less diversion, the more cash flows it possesses.

Using pure-strategy subgame-perfect equilibrium as our solution concept for the voting game, leaves us with a large number of equilibria. In fact, when no shareholder has more than $50 \%$ of the votes, it can be shown that 
any coalition can be supported as a winning board. ${ }^{4}$ Therefore, we use a cooperative refinement: In the voting game at date 1, we require that no coalition of shareholders can jointly deviate, and by doing so increase the payoff to each one of them. Thus, we require the equilibrium to be a strong equilibrium in the sense of Aumann (1959).

Intuitively, the coalition of board members must have sufficient voting power to be elected. In particular, since this coalition expropriates the coalition of non-board members, it must be able to beat this latter coalition at the shareholders' meeting. This gives rise to the concept of a strong coalition, which proves useful in characterizing the equilibria.

Definition 1. A strong coalition relative to the voting distribution $\mathbf{v}$ is a coalition in which either:

1. The sum of the votes of its members is strictly larger than 50\%, or

2. The sum of the votes is exactly $50 \%$ and the shareholder with the minimum index is a member.

Also, a weak coalition relative to $\mathbf{v}$ is one that is not strong relative to $\mathbf{v}$.

Before stating Proposition 1, we define $S(\mathbf{v})$ as the collection of all strong coalitions relative to a voting distribution $\mathbf{v}$. That is,

$$
S(\mathbf{v})=\{X \subseteq I: X \text { is strong relative to } \mathbf{v}\}
$$

Proposition 1. For the subgame that starts at date 1, an equilibrium always exists for any two distributions $\mathbf{c}$ and $\mathbf{v}$. Moreover, in all equilibria the winning coalition, $C^{*}$, is a strong coalition with the minimum cash flow of all strong coalitions. That is,

$$
C^{*} \in \underset{C \in S(\mathbf{v})}{\operatorname{argmin}} \sum_{i \in C} c_{i} .
$$

\footnotetext{
${ }^{4}$ Suppose every shareholder votes for coalition $D$, where $D$ is any coalition. No shareholder can, by unilaterally deviating, change the results of the election. Hence, this is an equilibrium.
} 
There might be many coalitions that minimize the sum of cash flows. In what follows, we assume that any of these coalitions is the winning coalition with equal probability. ${ }^{5}$

The result is intuitively appealing. The coalition of board members expropriates the coalition of non-board members. Hence, board members must have sufficient voting power to beat the coalition of non-board members, i.e., the winning board must be strong. Furthermore, the coalition with the smallest cash flow stake of all the strong coalitions wins because, of all the strong coalitions, it is the one whose members benefit the most from diversion since they have a "bigger" set (in terms of cash flows) of non-board members to expropriate from. This is what we termed the coalition formation effect in the Introduction. By selecting the strong coalition with the smallest cash flow stake, the coalition formation effect provides a counterweight to the entrepreneur's objective of maximizing the cash flow of the winning coalition. This tension, as we describe below, is what drives most of the results in our analysis.

There are two intermediate results needed for the proof of this proposition. We state them as lemmas and then sketch the proof of Proposition 1. The complete proof of this proposition, along with all other proofs, is in the appendix.

Lemma 2. Fix a cash flow distribution $\mathbf{c}$. The following holds:

i. A shareholder prefers being on the board to not being on the board.

ii. For any two boards in which a shareholder participates, she prefers the one with the smaller cash flow stake.

Part (i) is straightforward: a shareholder prefers to expropriate to being expropriated. Also, since a controlling coalition with a smaller cash flow stake diverts more than one with a larger cash flow stake (Lemma 1) a shareholder

\footnotetext{
${ }^{5}$ Note that unlike with the Nash equilibrium concept, existence of equilibrium is not guaranteed when the concept of strong equilibrium is used. However, due to our sharing rule, we have existence for every possible ownership structure.
} 
gets a larger fraction of the firm's revenue when she participates in the coalition with the smaller cash flow stake. This is the intuition for Part (ii). The next lemma establishes some of the properties of strong coalitions.

Lemma 3. Fix a voting distribution $\mathbf{v}$. The following holds:

i. A coalition is strong if and only if its complement (the coalition formed by the members that do not belong to it) is weak.

ii. Any two strong coalitions have at least one shareholder in common.

With these two lemmas, we can explain the result of Proposition 1. First, a weak coalition cannot be supported in equilibrium as the winning board. The reason is that if such a coalition were the winning board, the shareholders that do not belong to it would have a profitable deviation: voting for the coalition formed by themselves. By Lemma 3(i), the deviating coalition is strong, and hence it would be elected as the winning board. In addition, by Lemma 2(i), each of the members of the deviating coalition would be better off because, as a result of the deviation, they go from being expropriated to expropriating others.

Second, a strong coalition that does not minimize the sum of cash flows among the strong coalitions cannot be supported as the winning board. The reason is that, if such a coalition were the winning board, there would be a profitable deviation for the members of any strong coalitions with a smaller cash flow stake: voting for the coalition formed by themselves. Since the deviating coalition is strong it would win. Moreover, all the members of the deviating coalition would be better off. First, those who did not belong to the winning board at the proposed equilibrium would become board members. Hence, by Lemma 2(i), they would be better off. Second, those who did belong to the winning board at the proposed equilibrium would become board members of a board with a smaller cash flow stake. Thus, by Lemma 2(ii), they would also be better off.

Finally, there is always at least one equilibrium where the coalition that 
minimizes the sum of cash flows among the strong coalitions, $C^{*}$, wins. Indeed, we show that if everyone votes for $C^{*}$, no coalition of shareholders deviates. A coalition of shareholders that is weak cannot change the results of the election by deviating and hence we only consider deviations of strong coalitions. But every two strong coalitions have a shareholder in common (Lemma 3(ii)) and therefore one of the members of $C^{*}$ must belong to the deviating coalition. Since this shareholder is made better off by deviating then, by Lemma 2(i), she must be a member of the new board (the one resulting from the deviation) and, by Lemma 2(ii), this new board must have less cash flow than $C^{*}$. Hence, the new board is weak (by definition, no strong coalition can have less cash flow than $C^{*}$ ) and diverts more than $C^{*}$. But since the new board is weak but the deviating coalition is strong, there must be a deviating shareholder that is not in the new board. Since the new board diverts more than $C^{*}$, there is no way in which this shareholder can be better off. Therefore, no coalition deviates from the proposed equilibrium.

An additional simplification can be made to Proposition 1. The idea is that a strong coalition that has at least one strong proper subset is never the winning coalition. The reason is that such a coalition has more cash flow than its strong proper subset. Thus, it never has the minimum sum of cash flows among the strong coalitions. In order to find a winning coalition, attention can therefore be restricted to strong coalitions having the property that none of their proper subsets are strong. We call these coalitions relevant strong coalitions.

Definition 2. A relevant strong coalition relative to a voting distribution $\mathbf{v}$ is a strong coalition (relative to $\mathbf{v}$ ) whose proper subsets are all weak (relative to $\mathbf{v})$. In addition, a relevant shareholder is one that belongs to at least one relevant strong coalition. 
According to this discussion, equation (4) can be rewritten as:

$$
C^{*} \in \underset{C \in R(\mathbf{v})}{\operatorname{argmin}} \sum_{i \in C} c_{i},
$$

where $R(\mathbf{v})$ is the collection of all relevant strong coalitions relative to $\mathbf{v}$, that is,

$$
R(\mathbf{v})=\{X \subseteq I: X \text { is a relevant strong coalition relative to } \mathbf{v}\} .
$$

Relevant strong coalitions can be seen as the coalitions competing for control. These coalitions have the minimum number of shareholders necessary to amass sufficient votes to seize control. Members of a relevant strong coalition can obtain control and share the private benefits among themselves and, therefore, have no incentives to add additional shareholders.

An element of the range of $R(\cdot)$ is a collection of coalitions having the property that these coalitions are the only candidates to seize control of the firm. There are, in general, many voting distributions that generate the same collection of relevant strong coalitions. Interchanging any two such voting distributions (but keeping the distribution of cash flows fixed) does not affect the identity of the winning coalition, the amount of diversion, or the final payoff to each shareholder. That is, all the information about the voting distribution is summarized by the collection of relevant strong coalitions they generate. We refer to each of these collections as a control structure.

Definition 3. A control structure is a collection of all the relevant strong coalitions relative to some voting distribution.

We can then think of the entrepreneur as choosing, at date 0 , the number of shareholders, the control structure (which is equivalent to choosing any of the voting distributions that generate this control structure) and the cash flow distribution.

To clarify the concepts, we provide an example. Consider the voting distribution $(20 \%, 35 \%, 45 \%)$. The collection of strong coalitions relative to this 
voting distribution is $S((20 \%, 35 \%, 45 \%))=\{\{1,2\},\{1,3\},\{2,3\},\{1,2,3\}\}$. However, coalition $\{1,2,3\}$ is not relevant strong because some of its proper subsets are strong coalitions. Hence, the collection of relevant strong coalitions for this voting distribution is $R((20 \%, 35 \%, 45 \%))=\{\{1,2\},\{1,3\},\{2,3\}\}$. Similarly, starting from the voting distribution $\left(\frac{1}{3}, \frac{1}{3}, \frac{1}{3}\right)$, one obtains that $R\left(\left(\frac{1}{3}, \frac{1}{3}, \frac{1}{3}\right)\right)=\{\{1,2\},\{1,3\},\{2,3\}\}$. Therefore, we say that the voting distributions $\left(\frac{1}{3}, \frac{1}{3}, \frac{1}{3}\right)$ and $(20 \%, 35 \%, 45 \%)$ generate the same control structure $\{\{1,2\},\{1,3\},\{2,3\}\}$.

\section{One-share-one-vote}

In this section we apply Proposition 1 to gain insight into the optimal way of bundling cash flows and votes. We do not consider yet the complete problem of the entrepreneur (equation (2)) of designing at date 0 the ownership structure. Rather, we start with a given control structure and ask what is the cash flow profile that maximizes the value of the firm.

By Lemma 1, maximizing the value of the firm requires maximizing the cash flow stake of the board. Thus, given a control structure, the goal is to distribute cash flows so that the winning coalition has as much cash flows as possible.

To fix ideas we present an example before we state the main result of this section. Consider the control structure $\mathcal{R}=\{\{1,2\},\{1,3\},\{2,3\}\}$. There are many voting distributions that generate $\mathcal{R}$ (that is, many different v's such that $R(\mathbf{v})=\mathcal{R})$, but we know from our discussion above that the equilibrium is not affected by which of them we use.

Consider the cash flow distribution $(20 \%, 20 \%, 60 \%)$. The cash flows of the relevant strong coalitions $\{1,2\},\{1,3\}$, and $\{2,3\}$ are $40 \%, 80 \%$, and $80 \%$ respectively. Therefore, by Proposition 1, coalition $\{1,2\}$, which has $40 \%$ of the cash flow, would be the winning coalition.

Consider now the cash flow distribution $\left(\frac{1}{3}, \frac{1}{3}, \frac{1}{3}\right)$. All the relevant strong 
coalitions have cash flows of $\frac{2}{3}$, and therefore each has an equal probability of winning. Clearly, this cash flow distribution is better than the previous one, which yielded a winning coalition with cash flow of only $40 \%$. Moreover, it can be easily shown that the cash flow distribution $\mathbf{c}^{*}=\left(\frac{1}{3}, \frac{1}{3}, \frac{1}{3}\right)$ is the optimal distribution for this control structure. ${ }^{6}$

We are interested in the relation between the optimal cash flow distribution $\mathbf{c}^{*}$ and the voting distributions that generate the control structure $\mathcal{R}$. In this particular case, the voting distribution $\mathbf{v}^{*}=\left(\frac{1}{3}, \frac{1}{3}, \frac{1}{3}\right)$ generates the given control structure $\mathcal{R}=\{\{1,2\},\{1,3\},\{2,3\}\}$ (see the example at the end of the previous section). Hence, we say that there exists a one-share-one-vote ownership structure $\mathbf{v}^{*}=\mathbf{c}^{*}=\left(\frac{1}{3}, \frac{1}{3}, \frac{1}{3}\right)$ that maximizes efficiency for the given control structure $\mathcal{R}^{7}$

The previous example, though simple, might appear coincidental because, with three shareholders, there are not that many control structures. We provide briefly two additional examples with 5 shareholders before stating the main result. First, starting with the control structure $\mathcal{R}^{\prime}=\{\{2,3,4,5\}$, $\{1,5\},\{1,4\},\{1,3\},\{1,2\}\}$, we obtain (by solving a similar problem to that in footnote 6$)(3 / 7,1 / 7,1 / 7,1 / 7,1 / 7)$ as the optimal cash flow distribution. It can easily be checked that the voting distribution $(3 / 7,1 / 7,1 / 7,1 / 7,1 / 7)$ in turn generates the control structure $\mathcal{R}^{\prime}$. Another example is the control class $\mathcal{R}^{\prime \prime}=\{\{1,2,3\},\{1,2,4\},\{1,3,4\},\{1,5\},\{2,3,5\},\{2,4,5\},\{3,4,5\}\}$ with its corresponding optimal cash flow distribution $(2 / 7,1 / 7,1 / 7,1 / 7,2 / 7)$ which again generates $\boldsymbol{\mathcal { R }}^{\prime \prime}$.

\footnotetext{
${ }^{6}$ The problem to solve for this control structure is:

$$
\text { such that } c_{1}+c_{2}+c_{3}=1 \text {. }
$$$$
\max _{\mathbf{c}} \min \left\{c_{1}+c_{2}, c_{1}+c_{3}, c_{2}+c_{3}\right\}
$$

${ }^{7}$ This is not to say that this is the only ownership structure that maximizes efficiency in this control structure. Nor is it the case that any one-share-one-vote distribution is optimal for the control structure it generates. The result is weaker. It says that there is one one-share-one-vote ownership structure that maximizes efficiency.
} 
Proposition 2 generalizes these examples to any control structure. As noted above, maximizing efficiency is equivalent to maximizing the cash flow of the winning coalition. However, by Proposition 1, the winning coalition is the one with the minimum cash flow of all relevant strong coalitions. Therefore, the optimal cash flow distribution $\mathbf{c}^{*}$ for a given control structure $\mathcal{R}$ is the solution to the following problem:

$$
\max _{\mathbf{c}} \min _{C \in \mathcal{R}} \sum_{i \in C} c_{i}
$$

Proposition 2. Fix a control structure $\mathcal{R}$, and let $\mathbf{c}^{*}$ be the optimal cash flow distribution for this control structure. The voting distribution $\mathbf{v}^{*}=\mathbf{c}^{*}$ generates $\mathcal{R}$, i.e., $R\left(\mathbf{v}^{*}\right)=\mathcal{R}$.

The proposition states that, for any control structure, there is a one-shareone-vote ownership structure $\mathbf{v}^{*}=\mathbf{c}^{*}$ such that $\mathbf{c}^{*}$ is the optimal cash flow distribution for the given control structure, and $\mathbf{v}^{*}$ generates the given control structure. The result follows from the tension between the alignment effect, which requires that the winning coalition have the largest possible cash flow stake, and the coalition formation effect, which selects the relevant strong coalition with the smallest cash flow stake. We use this tension to show that the given control structure $\mathcal{R}$ and the control structure $R\left(\mathbf{v}^{*}\right)$ are, in fact, the same. To prove this fact, we show that the coalitions in $\mathcal{R}$ are relevant strong coalitions relative to $\mathbf{v}^{*} .8$

First, from her objective of increasing the cash flows of all the coalitions in $\mathcal{R}$, it can be shown that, at the solution $\mathbf{c}^{*}$, the entrepreneur obtains that the cash flows of all coalitions in $\mathcal{R}$ exceed $50 \%$. Since $\mathbf{v}^{*}=\mathbf{c}^{*}$, with the voting distribution $\mathbf{v}^{*}$, all coalitions in $\mathcal{R}$ have more than $50 \%$ of the votes, i.e., all coalitions in $\mathcal{R}$ are strong relative to $\mathbf{v}^{*}$.

Second, to explain how the equilibrium behavior works, we first state the following lemma:

\footnotetext{
${ }^{8}$ That is, we explain why $\mathcal{R} \subseteq R\left(\mathbf{v}^{*}\right)$. The proof of $R\left(\mathbf{v}^{*}\right) \subseteq \mathcal{R}$ is less interesting and can be found in the appendix.
} 
Lemma 4. Let shareholder $i_{0}$ be a member of coalition $C \in \mathcal{R}$. There exists a different coalition $D \in \mathcal{R}$ of which shareholder $i_{0}$ is a member such that,

$$
C-\left\{i_{0}\right\} \bigcap D-\left\{i_{0}\right\}=\emptyset
$$

This result says that for every coalition in $\mathcal{R}$, there is another coalition in $\mathcal{R}$ such that these two are "almost" disjoint. Intuitively, this result is related to the fact that the relevant strong coalitions have the minimum number of shareholders that ensures sufficient voting power.

Lemma 4 is useful for setting an upper bound on the cash flow that any of the coalitions in $\mathcal{R}$ have at the solution. The idea is simple. Imagine, just for the sake of explanation, that the objective is to maximize the minimum amount of cash flow possessed by each of two disjoint coalitions. Obviously, this cannot be larger than 50\%. A similar logic applies to the case where the two coalitions are "almost" disjoint in the sense of Lemma 4. In this case, however, the upper bound is such that the coalitions in $\mathcal{R}$ have cash flows that do not exceed $50 \%$ by "too much." This implies that when one shareholder in any of these coalitions is removed, the sum drops to a figure below $50 \%$. In terms of $\mathbf{v}^{*}\left(=\mathbf{c}^{*}\right)$ this implies that the coalitions in $\mathcal{R}$ are strong, but that when one shareholder is removed, the remaining shareholders form a weak coalition. But this is exactly what we wanted, because it implies that the coalitions in $\mathcal{R}$ are relevant strong relative to $\mathbf{v}^{*}$, i.e., $\mathcal{R} \subseteq R\left(\mathbf{v}^{*}\right)$.

The literature on the optimal bundling of cash flows and votes is extensive, originating from the work of Grossman and Hart (1988) and Harris and Raviv (1988). Most of these models derive the optimal bundling in the context of takeovers. Instead, we derive the optimality of one-share-one-vote in the absence of a potential takeover. Hence, our model is better suited to study firms in countries in which takeovers are rare. Indeed, our analysis is consistent with the empirical evidence of La Porta et al. (1999) that finds small deviations from one-share-one-vote in all the countries of their sample which includes many countries with no active markets for corporate control. 


\section{Ownership structure: the number and size of the shareholders}

In the last section, we discussed the properties of the best cash flow distribution for a given control structure. In this section, we are interested in the entrepreneur's complete problem of choosing at date 0 , the set of shareholders, the control structure and the cash flow distribution (equation (2)).

In principle, in order to solve the entrepreneur's complete problem, we need to consider every possible number of shareholders and, for a given number, all possible control structures. For each of these cases, we need to solve a problem similar to that in equation (6), adding the investor's wealth constraints. To simplify this tedious procedure, we state Proposition 3. In addition to simplifying the search for a solution, this proposition provides some interesting insights.

In Proposition 3 we start with a given number of shareholders: I relevant shareholders and any number of non-relevant shareholders and compute the best control structure and cash flow distribution. Proposition 3 takes the number of relevant shareholders as given and assumes that shareholders have enough wealth to buy the fraction of cash flow assigned to them at the solution. This is useful because it sets an upper bound to the payoffs the entrepreneur can obtain with a given number of relevant shareholders (obviously, introducing wealth constraints cannot improve the value of the maximization program).

As an illustration, suppose that with three shareholders, and considering wealth constraints, the entrepreneur manages to have a winning coalition with $66 \%$ of the cash flows. Should she consider solving the problem again for four shareholders? The answer is no because, by Proposition 3, with four shareholders, the winning coalition has a maximum cash flow stake of $60 \%$. Even more interestingly, there is no need to consider ownership structures with more than 3 shareholders because, as we show in Proposition 3, as the number 
of relevant shareholders is increased, efficiency is reduced.

We now state Proposition 3. Note that rather than providing the optimal control structure, we provide one of the voting distributions generating such a control structure. Not surprisingly, the ownership structures turn out to be one-share-one-vote ownership structures.

Proposition 3. Suppose the number of relevant shareholders is $I^{9}$ and there is any number of non-relevant shareholders. In the optimal ownership structure the non-relevant shareholders receive neither votes nor cash flows, the I relevant shareholders receive $(\mathbf{c}, \mathbf{v})$ and the cash flow stake the winning coalition is $\lambda$, where,

- If $I=1, \mathbf{c}=\mathbf{v}=1$ and $\lambda=1$.

- If $I \geq 3$ is odd, $\mathbf{c}=\mathbf{v}=\left(\frac{1}{I}, \frac{1}{I}, \ldots, \frac{1}{I}\right)$ and $\lambda=\frac{1}{2}+\frac{1}{2 I}$.

- If $I \geq 3$ is even, $\mathbf{c}=\mathbf{v}=\left(\frac{1}{I+1}, \frac{1}{I+1}, \ldots, \frac{2}{I+1}, \ldots, \frac{1}{I+1}\right)$, every shareholder has $\frac{1}{I+1}$ votes and cash flow except one - who can be anyone- who has $2 \frac{1}{I+1}$ and $\lambda=\frac{1}{2}+\frac{1}{2(I+1)}$.

Intuitively, small shareholders decrease efficiency because they tend to be included in the winning coalition but contribute little cash flow to it. The best way to distribute cash flows is then to spread them evenly across shareholders, since this maximizes the size of the smallest shareholder. The difference between the odd and even cases is due to the tie-breaking rule. However, the result and the intuition for both cases are similar.

Some comments relating to Proposition 3 are in order. First, it is clear that as the number of relevant shareholders increases, efficiency is reduced. This is because as cash flows and votes are distributed among more people, it is easier for a coalition with just enough votes and cash flows to form and be elected to the board. This may be one explanation for the fact that closely held corporations tend to have just a few shareholders.

\footnotetext{
${ }^{9}$ There do not exist control structures with two relevant shareholders.
} 
Second, the ownership structure of a firm will be either one in which there is one large shareholder or one in which there are many equal sized shareholders. ${ }^{10}$ Similar results can be found in Zwiebel (1995) and Burkart et al. (1997).

The third comment relates to the one-share-one-vote discussion of the previous section. By Proposition 2, we know that, for a given control class, there is a one-share-one-vote ownership structure that maximizes efficiency. However, this is not true for any one-share-one-vote ownership distribution. Nevertheless, the efficiency loss of using any one-share-one-vote distribution instead of the optimal distribution goes to zero as the number of relevant shareholders increases. This is because, as we saw in the proof of Proposition 2, any one-share-one-vote ownership distribution produces a winning coalition with more than $50 \%$ of the cash flow and, by Proposition 3, the cash flow of the winning coalition at the solution gets closer to $50 \%$ as the number of relevant shareholders increases. This result parallels those found for the optimality of one-share-one-vote when there is dispersed ownership. However, we are interested in cases in which there is a small number of shareholders. In these cases the efficiency loss of using any one-share-one-vote ownership structure could be significant.

Finally, as mentioned above, Proposition 3 is useful for solving the entrepreneur's complete problem (equation (2)). We solve this problem for a particular diversion technology in the following example.

\section{Example}

Suppose that the diversion technology is quadratic $B(d)=d-\frac{1}{2} d^{2}$. Furthermore, suppose for simplicity that the entrepreneur does not retain any cash flow or votes. Recall that the set of outside investors is $N$ and each one has a level of wealth $W_{i}$. Finally, suppose that the investment required $K<\frac{17}{18}$.

\footnotetext{
${ }^{10}$ When wealth constraints are included, they might prevent the entrepreneur from establishing an ownership structure with equal sized shareholders. However, the ownership structure she chooses would be as close as possible.
} 
This last inequality guarantees that the entrepreneur is able to raise sufficient funds to set up the firm even when diversion is as high as $\frac{1}{3}$.

We solve the above example for some possible values of $\left(W_{1}, \ldots, W_{N}\right)$.

Result: In this example, the entrepreneur's choice is given by:

1. If $W_{1} \geq \frac{13}{18}$, the best ownership structure is one where shareholder 1 has complete control (i.e., more than $50 \%$ of the votes) and as large a cash flow stake as she can afford. The rest of the cash flow and votes are sold to other investors; however, the number of investors or their size does not matter.

2. If $W_{1}, W_{2}$, and $W_{3}$ belong to the interval $\left[\frac{17}{54}, \frac{13}{18}\right)$, the optimal ownership structure is one where each one of them receives $\frac{1}{3}$ of both votes and cash flow.

We could continue doing this mapping from $\left(W_{1}, \ldots, W_{N}\right)$ to the optimal ownership structure; however, the two cases above are sufficient to illustrate the main points.

If the wealthiest investor has wealth $W_{1} \geq 1$, then first best can be achieved by selling the entire firm to this shareholder. However, if first best cannot be achieved, it does not necessarily imply that the entrepreneur should sell the firm to more than one relevant shareholder. Actually, by Proposition 3, we know that the best the entrepreneur can do with three (or more) relevant shareholders is that the winning coalition have $\frac{2}{3}$ of the cash flow. Hence, as long as there is one investor with enough wealth to buy more than $\frac{2}{3}$ of the cash flow, the ownership structure where this investor has strictly more than $50 \%$ of the votes is better than any other ownership structure.

To calculate the necessary wealth level, notice that the given diversion technology implies an equilibrium diversion level of $d^{*}=1-x$, where $x$ is the cash flow of the winning coalition. The dominant shareholder elects herself to 
the board and receives the entire private benefit. Hence, the value of buying more than $50 \%$ of the votes and $c_{1}$ cash flow for this shareholder is,

$$
\beta\left(1-d^{*}\right)+d^{*}-\frac{d^{*^{2}}}{2}=\frac{1}{2}\left(c_{1}^{2}+1\right) .
$$

This equation implies that the wealth needed to buy at least two thirds of the cash flow is $\frac{13}{18}$.

When none of the potential shareholders has sufficient wealth to buy at least $\frac{2}{3}$ of the cash flow, then an ownership structure with one relevant shareholder is not optimal. By Proposition 3, we know that the more relevant shareholders there are, the larger the efficiency loss. Hence, the natural step is to consider ownership structures with three relevant shareholders. Also, by Proposition 3, we know that the best ownership structure with three relevant shareholders is one where both votes and cash flows are distributed equally among shareholders, that is $\mathbf{v}=\mathbf{c}=\left(\frac{1}{3}, \frac{1}{3}, \frac{1}{3}\right)$. With this ownership structure, any coalition of 2 shareholders can become the winning board. Hence a shareholder is in the board with probability $\frac{2}{3}$ and when she is in the board she receives half the private benefits. All potential winning boards have cash flow of $\frac{2}{3}$ implying that $d^{*}=1-\frac{2}{3}=\frac{1}{3}$. At date 0 each of the future shareholders pays for the cash flow and private benefits she expects to receive:

$$
\frac{1}{3}\left(1-d^{*}\right)+\frac{2}{3} \frac{1}{2}\left(d^{*}-\frac{d^{*^{2}}}{2}\right)=\frac{17}{54} .
$$

This confirms part 2 of the result above.

Before leaving this section, we make a few comments. First, when $W_{1}$ is in the interval $\left[\frac{13}{18}, 1\right)$ the optimal ownership structure has one relevant and fairly large shareholder and (potentially many) non-relevant minority shareholders. Note that this ownership structure is not one of those prescribed in Proposition 3. This is because wealth constraints force the entrepreneur to deviate from an ownership structure where there is a shareholder with $100 \%$ of both cash flow and votes. That is, when wealth constraints are introduced, the 
resulting ownership structures are not necessarily those prescribed in Proposition 3. Nevertheless, this proposition gives some upper bounds which are helpful in reaching a solution.

Second, the entrepreneur chooses an ownership structure with three relevant shareholders, even when having one relevant shareholder and many nonrelevant shareholders is feasible. ${ }^{11}$ That is, our argument is not (the trivial one) that, when wealth constraints make having one relevant shareholder unachievable, the entrepreneur should add more relevant shareholders. Instead, the entrepreneur switches to three shareholders for efficiency reasons. By distributing power among three shareholders in such a way that no individual shareholder has absolute power, the entrepreneur forces shareholders to form a coalition to obtain control.

Finally, an ownership structure with equal-sized investors is not a consequence of equal wealth (actually, in our example we just require that each shareholder's wealth be in the interval $\left.\left[\frac{17}{54}, \frac{13}{18}\right)\right)$. Rather, it is the best way to avoid having small shareholders who contribute little cash flow to the winning coalition.

\section{Discussion}

Shareholders have access to mechanisms that reduce some of the conflicts we have analyzed in this paper. For instance, the corporate charter (or a shareholder agreement) may provide minority shareholders with veto rights on certain important policy issues, it may state that the board must be elected using a cumulative voting rule guaranteeing a place on the board for minority owners, or it may explicitly include the composition of the board.

Such initiatives improve efficiency in our model. Indeed first best can be obtain by contractually requiring that all shareholders have a place in the board. In such circumstances, our analysis would still be valid for at least

\footnotetext{
${ }^{11}$ It can be shown that this is the case when $W_{1}$ is in the interval $\left[2-i-\sqrt{2-2 i}, \frac{13}{18}\right)$ (this interval is not empty because $i<\frac{17}{18}$ ), and $W_{1}, W_{2}$, and $W_{3}$ belong to $\left[\frac{17}{54}, \frac{13}{18}\right.$ ).
} 
three reasons.

First, from the many cases brought to court and the many discussions in corporate law books, we conclude that not all conflicts between shareholders in closely held corporations are solved. In the absence of quantitative data on law cases, we briefly present the Levy versus Markal Sales Corporation case.

Markal Sales Corporation was founded in 1960 by Kenneth W. Levy. The corporation was involved in the sale of electronic equipment. Some years after the foundation, the corporation ownership structure consisted of three shareholders: Levy with $40 \%$ of the stock, Victor Gust with another 40\%, and Robert Bakal with the remaining 20\% (there were no deviations from one-share-one-vote). All the shareholders worked for the corporation and were involved in the management of it.

In 1980, Gust and Bakal voted to fire Levy as an employer of the corporation and effectively excluded him from management. Levy, however, kept his shares. Soon after, Gust was offered the opportunity to be a sales representative for Apple Computers who explicitly approached Markal because of its business reputation. However, instead of offering the opportunity to Markal, Gust and Bakal formed their own corporation, G/B Marketing, to represent Apple. Clearly, by doing so, Gust and Bakal diverted resources from Markal by stealing a project that belonged to the corporation.

After establishing G/B Marketing, Gust and Bakal diverted additional resources from Markal: Several G/B salespeople were on Markal payroll, expenses for business trips related to $\mathrm{G} / \mathrm{B}$ were charged to Markal, and $\mathrm{G} / \mathrm{B}$ rented office space from Markal at a price significantly below market value.

The Levy versus Markal Sales Corporation case fits nicely into our model, since it is a corporation with three significant owners. As our model predicts, a coalition seizes control and a conflict between this coalition and the remaining minority shareholder arises. Furthermore, the coalition that captures control has the minimum cash flow property as predicted by Proposition 1. Finally, the controlling coalition diverts significant amount of resources from the firm. 
On a more general level, O'Neal (1987), in his discussion of shareholder disputes in closely held corporations, observes "The most frequently occurring conflict of interest is between active shareholders, i.e. shareholder-officers or employees, and shareholders who are not active in the business." Furthermore, he explicitly acknowledges the role of a power contest within the closely held corporation and the difficulties in enforcing contracts among shareholders:

"Holders of a majority of the voting shares in a corporation, through their ability to elect and control a majority of the directors and to determine the outcome of shareholders' votes on other matters, have tremendous power to benefit themselves at the expense of minority shareholders....Traditionally, American courts have been reluctant to interfere in the internal affairs of corporations, even when minority shareholders claim they are being squeezed out or otherwise oppressed... Furthermore, many courts apparently feel that there is a legitimate sphere in which controlling shareholders can act in their own interest even if the minority suffers."

Second, even if there is a contract that gives every shareholder a seat on the board or veto power over all decisions, a coalition of shareholders would have incentives to invalidate such a contract. One way to accomplish this is to argue in court that the contract alters the statutory scheme (the system specified by law according to which corporations should be governed). Although US courts are now very flexible in the type of contracts that they uphold, this has not always been the case. In fact as Hamilton (1996) puts it: "Cases such as these, whether or not correctly decided, illustrate the pervasive impact of the statutory scheme on judicial thought and the danger of assuming that simply because all parties in interest agree to a variation in the statutory scheme, the variation is valid" (page 195, emphasis added). In our model, even a small probability that the agreement among shareholders will be invalidated and that the board will be determined by an election is enough to render our analysis valid.

Finally, even if it is feasible to protect minority shareholders through contracts and these contracts are enforceable in courts, giving control to all share- 
holders can be costly for reasons we do not model in this paper. It seems that, in general, there is a trade off between managerial flexibility and the degree of protection afforded to minority shareholders. If the corporate charter (or shareholder agreement) provides minority shareholders with few protections, they are vulnerable to the kind of inefficient exploitation that we have pursued in the present analysis. On the other hand, if minority shareholders are afforded too strong a protection, it may significantly restrict the controlling coalition's ability to govern the firm, and it may also raise the probability of costly deadlocks among the owners. Indeed, this trade-off is extensively discussed in the legal literature on closely held corporations. For instance, Easterbrook and Fischel (1991) notice that: "Drafters of the organizing documents of a closely held corporation cannot avoid a trade-off. On the one hand, they must provide some protection to minority investors to ensure that they receive an adequate return on the minority shareholder's investment if the venture succeeds. On the other hand, they cannot give the minority too many rights, for the minority might exercise their rights in opportunistic fashion to divert returns." 12

\section{Conclusions}

We have analyzed a model of a closely held corporation with non-transferable shares and potentially more than one significant shareholder. In the model the ownership structure determines which group of owners seizes control over the firm. We have argued that it may be in the initial owner's interest to dilute her own power by distributing votes among several large shareholders. This dilution of power commits the initial owner to form a coalition to obtain control, and thus creates a controlling body with more cash flow, and hence one that diverts less. In other words, we propose dilution of power as a mechanism to commit to low levels of diversion.

\footnotetext{
${ }^{12}$ This trade-off is analyzed in our related paper (Bennedsen and Wolfenzon (1999)).
} 
There are still many interesting topics about closely held corporations that we leave for future research. As suggested in the last section, among them is the analysis of the mechanisms of corporate governance that shareholders can design to mitigate the inefficiencies related to the exclusion of shareholders from the controlling coalition (what we termed the coalition formation effect). 


\section{Appendix}

\section{Proof of Lemma 2}

Let $C$ be the winning coalition. At date 2, members of $C$ choose the level of diversion. The payoff to each shareholder $i \in C$ is given by:

$$
c_{i}(1-d)+\frac{c_{i}}{\sum_{i \in C} c_{i}} B(d) .
$$

Each board member receives a fraction $c_{i}$ of the verifiable revenue $(1-d)$. In addition, board members split the private benefits $B(d)$ in proportion to their cash flows. The first order condition of each member of the winning coalition is the same, and hence they unanimously agree on the diversion level $d(C)$ defined by:

$$
B^{\prime}(d(C))=\sum_{i \in C} c_{i}
$$

The payoff to any shareholder $i$ when coalition $C$ wins is given by:

$$
U_{i}(C)= \begin{cases}c_{i}(1-d(C))+\frac{c_{i}}{\sum_{i \in C} c_{i}} B(d(C)) & \text { if } i \in C, \\ c_{i}(1-d(C)) & \text { otherwise. }\end{cases}
$$

Part (i): to show that if shareholder $i \in C$ and $i \notin D$ then $U_{i}(C) \geq U_{i}(D)$. Note that

$$
U_{i}(C) \geq c_{i}(1-d(D))+\frac{c_{i}}{\sum_{i \in C} c_{i}} B(d(D)) \geq c_{i}(1-d(D))=U_{i}(D),
$$

where the first inequality follows because $d(C)$ maximizes the expression in equation (7) for any member of $C$. Moreover, if $c_{i}>0$, the above inequality is strict. ${ }^{13}$

Part (ii): to show that if shareholder $i \in C, i \in D$, and $\sum_{i \in D} c_{i}>\sum_{i \in C} c_{i}$ then $U_{i}(C) \geq U_{i}(D)$.

Note that

$$
\begin{aligned}
U_{i}(C) \geq c_{i}(1-d(D))+\frac{c_{i}}{\sum_{i \in C} c_{i}} & B(d(D)) \\
& \geq c_{i}(1-d(D))+\frac{c_{i}}{\sum_{i \in D} c_{i}} B(d(D))=U_{i}(D),
\end{aligned}
$$

where the first inequality follows because $d(C)$ maximizes the expression in equation (7) for any member of $C$, and the second inequality follows from $\sum_{i \in D} c_{i}>$ $\sum_{i \in C} c_{i}$. Moreover, if $c_{i}>0$, the inequality is strict.

\section{Proof of Lemma 3}

Part (i): to show that, for any voting distribution $\mathbf{v}, C \in S(\mathbf{v})$ if and only if $C^{c} \notin S(\mathbf{v})$.

\footnotetext{
${ }^{13} c_{i}>0$ implies $\sum_{i \in D} c_{i}<1$ which, in turn implies that $B(d(D))>0$. Hence, the second inequality is strict.
} 
Take any $\mathbf{v}$, and suppose that $C \in S(\mathbf{v})$. Then either a) $\sum_{i \in C} v_{i}>50 \%$ or b) $\sum_{i \in C} v_{i}=50 \%$ and the entrepreneur belongs to $C$. In case a), $C^{c} \notin S(\mathbf{v})$ because $\sum_{i \in C^{c}} v_{i}<50 \%$. In case b) $C^{c} \notin S(\mathbf{v})$ because $\sum_{i \in C^{c}} v_{i}=50 \%$ and the entrepreneur is not a member of $C^{c}$ (he belongs to $C$ ). The proof of the other direction is similar.

Part (ii): to show that, for any voting distribution $\mathbf{v}$, if $C \in S(\mathbf{v})$ and $D \in S(\mathbf{v})$, then $C \cap D \neq \emptyset$.

Take any $\mathbf{v}$, and suppose (towards a contradiction) that $C \in S(\mathbf{v}), D \in S(\mathbf{v})$ and $C \cap D=\emptyset$. By definition of $S(\mathbf{v}), \sum_{i \in C} v_{i} \geq 50 \%, \sum_{i \in D} v_{i} \geq 50 \%$, and at least one of these inequalities is strict because the entrepreneur is at most in one of the two coalitions. But, $\sum_{i \in I} v_{i} \geq \sum_{i \in C} v_{i}+\sum_{i \in D} v_{i}>100$, where the first inequality follows from the fact that $C$ and $D$ are disjoint. Contradiction.

\section{Proof of Proposition 1}

Take any ownership structure $\mathbf{c}$, and $\mathbf{v}$. We divide the proof in three steps. ${ }^{14}$

Step 1: Weak boards are never supported in equilibrium.

Suppose (towards a contradiction) that the winning coalition $C$ is weak. ${ }^{15}$ Consider the following deviation: all the members of the coalition $C^{c}$ vote for the coalition $C^{c}$ at date $1 .{ }^{16}$ Since $C$ is weak, $C^{c}$ is strong (by Lemma 3(i)), and hence, as a result of the deviation, $C^{c}$ is elected. But, by Lemma 2(i), for any $i \in C^{c}$, $U_{i}\left(C^{c}\right)>U_{i}(C)$. Thus, every member of $C^{c}$ is better off, and as a result coalition $C^{c}$ deviates. Contradiction.

Step 2: Strong boards with more cash flow that the minimum among all strong coalitions are never supported in equilibrium.

Suppose towards a contradiction that the winning board $C$ is strong, and that there is another strong coalition $D$ such that $\sum_{i \in D} c_{i}<\sum_{i \in C} c_{i}$. Consider the following deviation: all the members of $D$ vote for coalition $D$ at date $1 .{ }^{17}$ Since $D$ is strong, as a result of the deviation, coalition $D$ is elected. Note that, by Lemma 2(i), for any $i \in D$ and $i \notin C, U_{i}(D)>U_{i}(C)$. And, because $\sum_{i \in D} c_{i}<\sum_{i \in C} c_{i}$, by Lemma 2(ii), for any $i \in D$ and $i \in C, U_{i}(D)>U_{i}(C)$. Thus, every member of $D$ is better off, and as a result coalition $D$ deviates. Contradiction.

Step 3: There is at least one equilibrium in which the strong coalition with the minimum cash flow among all strong coalitions is supported as the winning board.

The proof is by construction. Let $C$ be the strong coalition that minimizes the sum of cash flows among all strong coalitions. Consider the situation in which all

\footnotetext{
${ }^{14}$ For this proof and the following proofs we do not consider shareholders with 0 cash flow and positive votes. It can be shown that it is never optimal to have such a shareholder.

${ }^{15}$ In this proof we refer to coalitions as being weak or strong. These concepts are relative to the voting distribution $\mathbf{v}$.

${ }^{16}$ It is possible that, at the proposed equilibrium, some of the members of $C^{c}$ are already voting for coalition $C^{c}$ so, in fact, they do not deviate. However, it is impossible that all the members of $C^{c}$ are voting for $C^{c}$ at the proposed equilibrium, because if this was the case, the winning coalition would be $C^{c}$ and not $C$. To simplify exposition, we say that the "members of $C^{c}$ deviate," but it should be understood that only those who are not already voting for $C^{c}$ deviate.

${ }^{17} \mathrm{~A}$ similar comment to that in footnote (16) applies here.
} 
shareholders vote for coalition $C$ at date 1 . We show that no deviating coalition can make all of its members strictly better off.

Suppose (towards a contradiction) that coalition $D$ deviates at date 1 and, as a result of the deviation, all the members of coalition $D$ are made strictly better off. First, suppose that $D$ is weak. The results of the election are unchanged because coalition $D^{c}$, which still supports $C$, is strong (by Lemma 3(i)). Hence, the members of the deviating coalition are indifferent. Contradiction.

Second, suppose that $D$ is strong, and that, as a result of the deviation, coalition $E$ is elected as the board. Note that $E \neq D$ because otherwise the members of the deviating coalition would be indifferent. Since both $C$ and $D$ are strong, by Lemma 3(ii), they have at least one shareholder, $j$, in common $(j \in C \cap D)$. Since shareholder $j \in C$, it must be that $j \in E$, otherwise she would be made worse off by deviating (by Lemma 2(i)). Also, it must be that $\sum_{i \in E} c_{i}<\sum_{i \in C} c_{i}$, otherwise shareholder $j$ would be indifferent or worse off by deviating (by Lemma 2(ii)). This last inequality has two implications. One is that coalition $E$ diverts more than coalition $C$. The other is that coalition $E$ is weak because no strong coalition has strictly less cash flow than $C$. But since $D$ is strong and $E$ is weak, there must be at least one shareholder, $k$, such that $k \in D$ and $k \notin E$ (obviously, a strong coalition can not be a subset of a weak coalition). We show that shareholder $k$ is worse off by deviating. If shareholder $k \in C$, then since $k \notin E$, by Lemma $2(\mathrm{i}), U_{k}(E)<U_{k}(C)$ (shareholder $k$ losses her position in the board). And, if shareholder $k \notin C$ (he is not in the board in any case), he is also made worse off by deviating, because board $E$ diverts more than board $C$. Contradiction.

The fact that the level of diversion is a decreasing function of the cash flow of the winning coalition can be obtained from equation (8) and the fact that $B^{\prime \prime}(\cdot)<0$.

\section{Proof of Lemma 4}

We start with a given control structure $\mathcal{R}$, and a shareholder $i$ that belongs to $C \in \mathcal{R}$. Let $\overline{\mathbf{v}}$ be one of the voting distributions that generate $\mathcal{R}$ (i.e., $R(\overline{\mathbf{v}})=\mathcal{R})$. Now, $C \in R(\overline{\mathbf{v}})$ only if $C \in S(\overline{\mathbf{v}})$. This implies that $C^{c} \notin S(\overline{\mathbf{v}})$. Also, since $C \in R(\overline{\mathbf{v}})$ it must be that $C-\{i\} \notin S(\overline{\mathbf{v}})$ (recall that relevant strong coalitions are strong coalitions with weak proper subsets). Thus, $(C-\{i\})^{c}=C^{c} \cup\{i\} \in S(\overline{\mathbf{v}})$. Therefore, there must be $D \subseteq C^{c} \cup\{i\}$ such that $D \in R(\overline{\mathbf{v}}) \cdot{ }^{18}$ Note that $i \in D$ because otherwise $D \subseteq C^{c}$. But, since $C^{c}$ is weak, so would $D$ (clearly, a subset of a weak coalition is weak) and hence it would not be in $R(\overline{\mathbf{v}})$. Finally, by construction $D-\{i\} \subseteq C^{c}$, and therefore $C-\{i\} \cap D-\{i\}=\emptyset$.

\section{Proof of Proposition 2}

We start with a given control structure, $\mathcal{R}$. Recall that the cash flow distribution that maximizes efficiency for this control structure is the solution to equation (6),

\footnotetext{
${ }^{18}$ We are using the following fact: for any $\mathbf{v} F \in S(\mathbf{v}) \Longrightarrow \exists G \subseteq F, G \in R(\mathbf{v})$. This fact seems straightforward. However, for completeness we prove it here. The proof is by induction on the number of elements of $F$.

For $\# F=1$, if $F \in S(\mathbf{v})$, then it must be that $F \in R(\mathbf{v})$ because the only proper subset of $F$ is $\emptyset$ which is weak.

Suppose, the statement holds for $\# F=n$, and consider the case where $\# F=n+1$ and $F \in S(\mathbf{v})$. If $\forall j, F-\{j\} \notin S(\mathbf{v})$, then clearly all the subsets of $F$ are weak and therefore $F \in R(\mathbf{v})$. If, instead, $\exists \bar{\jmath} F-\{\bar{\jmath}\} \in S(\mathbf{v})$, then since $\# F-\{\bar{\jmath}\}=n$ there is $G \subseteq F-\{\bar{\jmath}\}, G \in R(\mathbf{v})$. But $G \subseteq F-\{\bar{\jmath}\} \subset F$.
} 
which we rewrite here:

$$
\max _{\mathbf{c}} \min _{C \in \mathcal{R}} \sum_{i \in C} c_{i},
$$

where $\mathbf{c} \geq 0$ and $\sum_{i \in I} c_{i}=1$. We denote by $\mathbf{c}^{*}$ the cash flow distribution that solves equation (6), and by $\lambda$ the value of the program.

The objective of the proof is to show that the voting distribution $\mathbf{v}^{*}=\mathbf{c}^{*}$ generates the control structure $\mathcal{R}$, that is, $R\left(\mathbf{v}^{*}\right)=\mathcal{R}$. This is done in a number of steps.

Step 1: A solution to equation (6) exists.

Since for a fixed $C, \sum_{i \in C} c_{i}$ is a continuous function of the $c_{i}$ 's and the minimum of a number of continuous functions is continuous, the problem of equation (6) is one of a continuous function over a compact set.

Step 2: At the solution $\mathbf{c}^{*}$, for any coalition $C \in \mathcal{R}, \sum_{i \in C} c_{i}^{*}>\frac{1}{2}$.

It is enough to show that $\lambda>\frac{1}{2}$. Take any voting distribution $\overline{\mathbf{v}}$ such that $R(\overline{\mathbf{v}})=$ $\boldsymbol{R}$. Now, $C \in R(\overline{\mathbf{v}})$ only if $C \in S(\overline{\mathbf{v}})$ which implies that either $\sum_{i \in C} \bar{v}_{i}>\frac{1}{2}$, or $\sum_{i \in C} \bar{v}_{i}=\frac{1}{2}$ and the entrepreneur is a member of $C$.

First, suppose that, for $\overline{\mathbf{v}}$, all coalitions $C \in R(\overline{\mathbf{v}})$ are such that $\sum_{i \in C} \bar{v}_{i}>\frac{1}{2}$. Consider the cash flow distribution $\overline{\mathbf{c}}=\overline{\mathbf{v}}$. Hence, for any $C \in R(\overline{\mathbf{v}}), \sum_{i \in C} \bar{c}_{i}=$ $\sum_{i \in C} \bar{v}_{i}>\frac{1}{2}$. But this implies that

$$
\lambda \geq \min _{C \in R(\overline{\mathbf{v}})} \sum_{i \in C} \bar{c}_{i}>\frac{1}{2},
$$

where the first inequality follows because $\overline{\mathbf{c}}$ is not necessarily the optimal cash flow distribution.

Second, suppose that for $\overline{\mathbf{v}}$ some of the coalitions in $R(\overline{\mathbf{v}})$ have exactly $\frac{1}{2}$ of the votes and include the entrepreneur. It is easy to check that $\overline{\mathbf{v}}$ can be perturbed to obtain another voting distribution that also generates $\mathcal{R}$, and such that every relevant strong coalition has strictly more than $\frac{1}{2}$ of the votes. ${ }^{19}$ Hence, we can apply the argument of the previous paragraph to the perturbed voting vector.

Step 3: For any coalition $C \in \mathcal{R}$ and any shareholder $j \in C, \sum_{i \in C} c_{i}^{*}-c_{j}^{*}<\frac{1}{2}$.

Suppose not. This implies that there is at least one coalition $E \in \mathcal{R}$ and one shareholder $i_{0} \in E$ such that $\sum_{i \in E} c_{i}^{*}-c_{i_{0}}^{*} \geq \frac{1}{2}$. By Lemma 4, there is another coalition $D \in \mathcal{R}$ that includes $i_{0}$ and such that $E-\left\{i_{0}\right\} \cap D-\left\{i_{0}\right\}=\emptyset$. But,

$$
\begin{aligned}
\sum_{i \in I} c_{i}^{*} & \geq\left(\sum_{i \in E} c_{i}^{*}-c_{i_{0}}^{*}\right)+\left(\sum_{i \in D} c_{i}^{*}-c_{i_{0}}^{*}\right)+c_{i_{0}}^{*} \\
& =\left(\sum_{i \in E} c_{i}^{*}-c_{i_{0}}^{*}\right)+\sum_{i \in D} c_{i}^{*} \\
& >1 \quad \text { Contradiction! }
\end{aligned}
$$

\footnotetext{
${ }^{19}$ Consider the perturbed voting vector $v_{1}^{p}=\bar{v}_{1}+\epsilon$ and $v_{i}^{p}=\bar{v}_{i}+\frac{\epsilon}{I-1} \quad$ for $\quad i=2, \ldots, I$ (recall shareholder 1 is the entrepreneur). It can be shown that for a sufficiently small $\epsilon$ the desired result holds.
} 
The first inequality uses the fact that, because $E-\left\{i_{0}\right\} \cap D-\left\{i_{0}\right\}=\emptyset, E-\left\{i_{0}\right\}$, $D-\left\{i_{0}\right\}$, and $\left\{i_{0}\right\}$ are mutually disjoint sets. The last inequality uses the fact $\sum_{i \in E} c_{i}^{*}-c_{i_{0}}^{*} \geq \frac{1}{2}$, and the fact that, since $D \in \mathcal{R}$, by step $2, \sum_{i \in D} c_{i}^{*}>\frac{1}{2}$.

Step 4: The voting distribution $\mathbf{v}^{*}=\mathbf{c}^{*}$ is such that $R\left(\mathbf{v}^{*}\right)=\mathcal{R}$.

First, we show $\mathcal{R} \subseteq R\left(\mathbf{v}^{*}\right)$. Take any coalition $C \in \mathcal{R}$. Note that, $\sum_{i \in C} v_{i}^{*}=$ $\sum_{i \in C} c_{i}^{*}>\frac{1}{2}$, where the inequality follows from step 2. This implies that $C \in S\left(\mathbf{v}^{*}\right)$. Now, take any proper subset $D \subset C$. There exists at least a shareholder $i_{0} \in C$ such that $i_{0} \notin D$, or $D \subseteq C-\left\{i_{0}\right\}$. This implies that,

$$
\sum_{i \in D} v_{i}^{*}=\sum_{i \in D} c_{i}^{*} \leq \sum_{i \in C} c_{i}^{*}-c_{i_{0}}^{*}<\frac{1}{2},
$$

where the first inequality follows from $D \subseteq C-\left\{i_{0}\right\}$ and the last one follows from step 3. This implies $D \notin S\left(\mathbf{v}^{*}\right)$, that is, any proper subset of $C$ is weak relative to $\mathbf{v}^{*}$. This fact, together with the fact that $C \in S\left(\mathbf{v}^{*}\right)$, implies that $C \in R\left(\mathbf{v}^{*}\right)$.

Second, we show that $R\left(\mathbf{v}^{*}\right) \subseteq \mathcal{R}$. Suppose (towards a contradiction) that there is a $C \in R\left(\mathbf{v}^{*}\right)$ and $C \notin \mathcal{R}$. Let $\overline{\mathbf{v}}$ be one of the voting distributions that generate $\mathcal{R}$, that is, $R(\overline{\mathbf{v}})=\mathcal{R}$. Now, $C \notin \mathcal{R}=R(\overline{\mathbf{v}})$ implies that either a) $C \notin S(\overline{\mathbf{v}})$, or b) $C \in S(\overline{\mathbf{v}})$ and there is $D \in S(\overline{\mathbf{v}})$ such that $D \subset C$.

In case a), $C \notin S(\overline{\mathbf{v}})$ implies $C^{c} \in S(\overline{\mathbf{v}})$. Therefore, there must be $E \subseteq C^{c}$ such that $E \in R(\overline{\mathbf{v}}) \cdot{ }^{20}$ But, because $R(\overline{\mathbf{v}})=\mathcal{R} \subseteq R\left(\mathbf{v}^{*}\right), E \in R(\overline{\mathbf{v}})$ implies that $E \in R\left(\mathbf{v}^{*}\right)$. Therefore, both $C$ and $E$ belong to $R\left(\mathbf{v}^{*}\right)$, and this implies that both coalitions belong to $S\left(\mathbf{v}^{*}\right)$. But, by construction $C \cap E=\emptyset$ which is a contradiction because, relative to any voting distribution, two strong coalitions have at least one shareholder in common (see Lemma 3(ii))

In case b), $D \in S(\overline{\mathbf{v}})$ implies that there is $F \subseteq D$ such that $F \in R(\overline{\mathbf{v}}) .^{21}$ Because $R(\overline{\mathbf{v}})=\mathcal{R} \subseteq R\left(\mathbf{v}^{*}\right), F \in R(\overline{\mathbf{v}})$ implies that $\bar{F} \in R\left(\mathbf{v}^{*}\right)$. Now $F \in R\left(\mathbf{v}^{*}\right)$ only if $F \in S\left(\mathbf{v}^{*}\right)$. But $F \subseteq D \subset C$ and $F \in S\left(\mathbf{v}^{*}\right)$ imply that $C \notin R\left(\mathbf{v}^{*}\right)(C$ cannot be a relevant strong coalition relative to $\mathbf{v}^{*}$ because $F$ is strong relative to $\mathbf{v}^{*}$ and is a subset of $C)$. But by assumption $C \in R\left(\mathbf{v}^{*}\right)$. Contradiction.

\section{Proof of Proposition 3}

We start with $I$ relevant shareholders and any number of non-relevant shareholders. We are looking for the control structure having $I$ relevant shareholders and the associated cash flow distribution that maximizes the cash flow of the winning coalition. They can be found by solving, for each control structure $\mathcal{R}$ having $I$ relevant shareholders, the program in equation (6):

$$
\max _{\mathbf{c}} \min _{C \in \mathcal{R}} \sum_{i \in C} c_{i}
$$

We denote by $\mathbf{c}^{*}(\boldsymbol{R})$ the cash flow distribution that solves this program for the control structure $\mathcal{R}$, and by $\lambda(\mathcal{R})$ the value of the program for the control structure $\mathcal{R}$.

The proof is organized in a series of steps.

\footnotetext{
${ }^{20}$ See footnote 18.

${ }^{21}$ Again, see footnote 18.
} 
Step 1: At the solution non-relevant shareholders receive zero cash flow. As a normalization they are assigned no votes either.

In fact, it is possible that non-relevant shareholders have some votes, as long as they are few enough to guarantee that they do not belong to any relevant strong coalition. However, as a normalization, we assign 0 votes to each one of them.

The fact that they receive zero cash flow is straightforward. Suppose (towards a contradiction) that non-relevant shareholders receive some positive amount of cash flows, $c>0$. Consider, a different cash flow distribution where the amount $c$ is distributed evenly to all relevant shareholders. This redistribution raises the cash flow of every relevant strong coalition. Therefore, the new distribution must result in a winning board with more cash flow. Clearly then having $c>0$ is not optimal.

Step 2: For $I=1, \mathbf{c}=\mathbf{v}=1$ with corresponding $\lambda=1$.

This ownership structure is the first best ownership structure.

Step 3: For $I \geq 3$ and $I$ odd, $\mathbf{c}=\mathbf{v}=\left(\frac{1}{I}, \ldots, \frac{1}{I}\right)$ with corresponding $\lambda=\frac{1}{2}+\frac{1}{2 I}$.

Take any control structure $\mathcal{R}$. Let $i_{\min }$ be the relevant shareholder with the least cash flow at the solution. Since $i_{\min }$ is a relevant shareholder it must belong to some coalition $C \in \mathcal{R}$. By Lemma 4 , there is another coalition $D \in \mathcal{R}$ such that $i_{\min } \in D$ and $C-\left\{i_{\min }\right\} \cap D-\left\{i_{\min }\right\}=\emptyset$. Now,

$$
\begin{aligned}
1=\sum_{i \in I} c_{i}^{*}(\mathcal{R}) & \geq\left(\sum_{i \in C} c_{i}^{*}(\mathcal{R})-c_{i_{\min }}^{*}(\mathcal{R})\right)+\left(\sum_{i \in D} c_{i}^{*}(\mathcal{R})-c_{i_{\min }}^{*}(\mathcal{R})\right)+c_{i_{\min }}^{*}(\mathcal{R}) \\
& =\sum_{i \in C} c_{i}^{*}(\mathcal{R})+\sum_{i \in D} c_{i}^{*}(\mathcal{R})-c_{i_{\min }}^{*}(\mathcal{R}) \\
& \geq 2 \lambda(\mathcal{R})-c_{i_{\min }}^{*}(\mathcal{R})
\end{aligned}
$$

The first inequality uses the fact that, because $C-\left\{i_{\min }\right\} \cap D-\left\{i_{\min }\right\}=\emptyset, C-\left\{i_{\min }\right\}$, $D-\left\{i_{\min }\right\}$, and $\left\{i_{\min }\right\}$ are mutually disjoint sets. The last inequality uses the fact that both $C$ and $D$ belong to $\mathcal{R}$, and hence it must be that $\sum_{i \in C} c_{i}^{*}(\mathcal{R}) \geq \lambda(\mathcal{R})$ and $\sum_{i \in D} c_{i}^{*}(\mathcal{R}) \geq \lambda(\mathcal{R})$ (recall that the winning coalition is the one among all relevant strong coalition with the least cash flow). Therefore,

$$
\forall \mathcal{R}, \lambda(\mathcal{R}) \leq \frac{1}{2}+\frac{c_{i_{\min }^{*}}^{*}(\mathcal{R})}{2} .
$$

Note that this equation holds for any control structure because we have not introduced yet the condition that $I$ is odd. When $\mathcal{R}$ has $I$ relevant shareholders, $c_{i_{\min }}^{*}(\mathcal{R}) \leq \frac{1}{I}$ and therefore

$$
\forall \mathcal{R} \text { with } I \text { relevant shareholders, } \lambda(\mathcal{R}) \leq \frac{1}{2}+\frac{1}{2 I},
$$

Finally, we show that, for $I$ odd, this upper bound can be attained with the ownership structure $\mathbf{c}=\mathbf{v}=\left(\frac{1}{I}, \ldots, \frac{1}{I}\right)$. Therefore, this ownership structure is optimal. It can easily be seen that a coalition is relevant strong relative to $\mathbf{v}$ if and only if it contains any $\frac{I+1}{2}$ shareholders. The cash flow of any of the relevant strong coalitions is $\frac{1}{2}+\frac{1}{2 I}$ and hence this is also the cash flow of the winning one. Hence the upper bound is achieved. 
The rest of the proof is for the case where $I$ is even. In this case the upper bound $\frac{1}{2}+\frac{1}{2 I}$ cannot be attained with any control structure. However, when $I$ is even, it can be shown that there is a lower upper bound given by $\frac{1}{2}+\frac{1}{2(I+1)}$. This is done in step 4 . In step 5 we show that there is an ownership structure that attains this upper bound.

Step 4: For any control structure $\mathcal{R}$ with $I$ ( $I$ even) relevant shareholder

$$
\lambda(\mathcal{R}) \leq \frac{1}{2}+\frac{1}{2(I+1)}
$$

Let $\mathcal{R}$ be such a control structure and let $i_{\min }$ and $i_{\max }$ be the shareholders with the least and the most cash flow at the solution. For a control class with an even number of relevant shareholders the following holds:

$$
\lambda(\mathcal{R}) \leq \frac{1}{2}+\frac{c_{i_{\max }^{*}}^{*}(\mathcal{R})-c_{i_{\min }}^{*}(\mathcal{R})}{2}
$$

In order not to disrupt the flow of this proof, we prove this result at the end.

Consider two cases. Case 1$)$ is $c_{i_{\max }^{*}}^{*}(\mathcal{R})>c_{i_{\min }^{*}}^{*}(\mathcal{R})+\frac{1}{I+1}$. Note that

$$
1=\sum_{i \in I} c_{i}^{*}=\sum_{i \in I-\left\{i_{\max }\right\}} c_{i}^{*}(\mathcal{R})+c_{i_{\max }}^{*}(\mathcal{R})>(I-1) c_{i_{\min }}^{*}(\mathcal{R})+c_{i_{\min }}^{*}(\mathcal{R})+\frac{1}{I+1} .
$$

Hence $c_{i_{\min }}^{*}(\mathcal{R})<\frac{1}{I+1}$, and therefore,

$$
\lambda(\mathcal{R}) \leq \frac{1}{2}+\frac{c_{i_{\min }}^{*}(\mathcal{R})}{2}<\frac{1}{2}+\frac{1}{2(I+1)},
$$

where the first inequality follows from equation (10).

Case 2) is where $c_{i_{\max }}^{*}(\mathcal{R}) \leq c_{i_{\min }}^{*}(\mathcal{R})+\frac{1}{I+1}$. Then

$$
\lambda(\mathcal{R}) \leq \frac{1}{2}+\frac{c_{i_{\max }}^{*}(\mathcal{R})-c_{i_{\min }}^{*}(\mathcal{R})}{2} \leq \frac{1}{2}+\frac{1}{2(I+1)}
$$

Where the first inequality follows from equation (12).

Step 5: For $I \geq 3$ and $I$ even, $\mathbf{c}=\mathbf{v}=\left(\frac{1}{I+1}, \ldots, 2 \frac{1}{I+1}, \ldots, \frac{1}{I+1}\right)$ (every shareholder has cash flow and votes $\frac{1}{I+1}$ except one - who can be anyone- who has $\left.2 \frac{1}{I+1}\right)$ with corresponding $\lambda=\frac{1}{2}+\frac{1}{2(I+1)}$.

Since, by the previous step, no control structure with $I$ even shareholders can do better than $\frac{1}{2}+\frac{1}{2(I+1)}$, it is sufficient to show that the proposed ownership structure attains this upper bound.

Let $i_{0}$ be the shareholder that receives cash flow and votes $2 \frac{1}{I+1}$. The relevant strong coalitions that this voting distribution generates are of two types, either: 1) they include $i_{0}$ and any other $\frac{I}{2}-1$ shareholders, or 2) they have $\frac{I}{2}+1$ shareholders none 
of which is $i_{0}$. Each relevant strong coalition has cash flow of $\frac{1}{2}+\frac{1}{2(I+1)}$ and hence this must be the cash flow of the winning coalition.

We now prove the result in equation (12).

For any control structure $\mathcal{R}$ with $I$ ( $I$ even) relevant shareholders:

$$
\lambda(\mathcal{R}) \leq \frac{1}{2}+\frac{c_{i_{\max }}^{*}(\mathcal{R})-c_{i_{\min }}^{*}(\mathcal{R})}{2}
$$

Take any voting distribution $\mathbf{v}$ such that $R(\mathbf{v})=\mathcal{R}$. Let $\pi$ be a permutation of $I$ that "orders" $\mathbf{v}$ as follows:

$$
v_{\pi(1)} \leq v_{\pi(2)} \cdots \leq v_{\pi(I)},
$$

with the condition that if there are many $v_{i}$ 's that attain the maximum and the entrepreneur is one of them, then $\pi(I)$ is the entrepreneur (or $\pi(I)=1$ ).

First we show that there exists $C$ and $D$ such that

1) $C \cup D=I-\{\pi(I), \pi(1)\}$,

2) $C \cap D=\emptyset$, and

3) $C \cup\{\pi(I)\} \in S(\mathbf{v})$ and $D \cup\{\pi(I)\} \in S(\mathbf{v})$.

¿From this the inequality in equation (12) will follow immediately.

Consider arranging the shareholders $\pi(2), \ldots, \pi(I-1)$ into coalitions $C$ and $D$ as follows:

$$
\begin{aligned}
C & =\{\pi(2), \ldots, \pi(2 n), \ldots, \pi(I-2)\} \\
D & =\{\pi(3), \ldots, \pi(2 n+1), \ldots, \pi(I-1)\}
\end{aligned}
$$

We only need to show that $C \cup\{\pi(I)\} \in S(\mathbf{v})$ and $D \cup\{\pi(I)\} \in S(\mathbf{v})$. The rest of the statement holds by construction.

Let $\Delta_{i}=v_{\pi(i)}-v_{\pi(i-1)}$ for $i=2, \ldots, I$. Hence $\Delta_{i} \geq 0$ and $\sum_{i=2}^{I} \Delta_{i}=v_{\pi(I)}-v_{\pi(1)}$. Now:

$$
\begin{aligned}
\sum_{i \in D} v_{i}-\sum_{i \in C} v_{i} & =\Delta_{3}+\cdots+\Delta_{2 n+1}+\cdots+\Delta_{I-1} \\
& \leq v_{\pi(I)}-v_{\pi(1)} .
\end{aligned}
$$

In addition, from the fact that $\Delta_{i} \geq 0$ and the above equation, $\sum_{i \in D} v_{i} \geq \sum_{i \in C} v_{i}$. By construction $\sum_{i \in D} v_{i}+\sum_{i \in C} v_{i}=1-\left(v_{\pi(1)}+v_{\pi(I)}\right)$. Hence,

$$
\begin{aligned}
\sum_{i \in C} v_{i}+v_{\pi(I)} & =\frac{\left(\sum_{i \in D} v_{i}+\sum_{i \in C} v_{i}\right)-\left(\sum_{i \in D} v_{i}-\sum_{i \in C} v_{i}\right)}{2}+v_{\pi(I)} \\
& =\frac{1-\left(v_{\pi(1)}+v_{\pi(I)}\right)-\left(\sum_{i \in D} v_{i}-\sum_{i \in C} v_{i}\right)}{2}+v_{\pi(I)} \\
& =\frac{1+\left(v_{\pi(I)}-v_{\pi(I)}\right)-\left(\sum_{i \in D} v_{i}-\sum_{i \in C} v_{i}\right)}{2} \\
& \geq \frac{1}{2}
\end{aligned}
$$


Where the last line follows from the inequality in equation (14).

We consider two cases. Case 1) is one in which the inequality in equation (14) is strict. Then equation (15) implies that $\sum_{i \in C} v_{i}+v_{\pi(I)}>\frac{1}{2}$, or equivalently that $C \cup\{\pi(I)\} \in S(\mathbf{v})$. Also, since $\sum_{i \in D} v_{i} \geq \sum_{i \in C} v_{i}, \sum_{i \in D} v_{i}+v_{\pi(I)}>\frac{1}{2}$, and so $D \cup\{\pi(I)\} \in S(\mathbf{v})$

Case 2 ) is one in which equation (14) holds with equality. This implies that $\Delta_{3}+$ $\cdots+\Delta_{2 n+1}+\cdots+\Delta_{I-1}=v_{\pi(I)}-v_{\pi(1)}$ and hence $\Delta_{k}=0$ for $k$ even. ¿From equation (15) we obtain that $\sum_{i \in C} v_{i}+v_{\pi(I)}=\frac{1}{2}$. Therefore we cannot be sure that coalition $A \cup\{\pi(I)\} \in S(\mathbf{v})$, as it is not clear that the entrepreneur is a member. We consider three subcases. Case 2a) is when there is $\Delta_{2 i+1} \geq \Delta_{2 j+1}>0$. In this case, we consider a slight variation from the coalitions $C$ and $D$. We switch shareholders $2 j$ and $2 j+1$ as follows:

$$
\begin{aligned}
C^{\prime} & =\{\pi(2), \ldots, \pi(2 i), \ldots, \boldsymbol{\pi}(\mathbf{2} \mathbf{j}+\mathbf{1}), \ldots, \pi(I-2)\} \\
D^{\prime} & =\{\pi(3), \ldots, \pi(2 i+1), \ldots, \boldsymbol{\pi}(\mathbf{2} \mathbf{j}), \ldots, \pi(I-1)\} .
\end{aligned}
$$

So the difference between the votes of coalitions $C^{\prime}$ and $D^{\prime}$ is now:

$$
\sum_{i \in D^{\prime}} v_{i}-\sum_{i \in C^{\prime}} v_{i}=\Delta_{3}+\cdots+\Delta_{2 i+1}+\cdots-\Delta_{2 \mathbf{j}+\mathbf{1}}+\cdots+\Delta_{I-1}
$$

The difference is nonnegative and strictly smaller than $v_{\pi(I)}-v_{\pi(1)}$. A similar calculation to that in equation (15) shows that $\sum_{i \in C^{\prime}} v_{i}+v_{\pi(I)}>\frac{1}{2}$, and so $C^{\prime} \cup$ $\{\pi(I)\} \in S(\mathbf{v})$. Also, since $\sum_{i \in D^{\prime}} v_{i} \geq \sum_{i \in C^{\prime}} v_{i}, \sum_{i \in D^{\prime}} v_{i}+v_{\pi(I)}>\frac{1}{2}$, and so $D^{\prime} \cup\{\pi(I)\} \in S(\mathbf{v})$

Case $2 \mathrm{~b}$ ) is when there is a unique $i \geq 1$ such that $\Delta_{2 i+1}>0$. This implies that the elements of the voting distribution take only two values $\bar{v}$ and $\underline{v}(\bar{v}>\underline{v})$. And, since $\Delta_{2 i+1}>0$, then from equation (14), $\sum_{i \in D} v_{i}>\sum_{i \in C} v_{i}$.

If the entrepreneur has $\bar{v}$ votes, he is shareholder $\pi(I)$ (recall the rules for $\pi(\cdot)$ ), and hence coalition $C \cup\{\pi(I)\} \in S(\mathbf{v})$ because it has $\frac{1}{2}$ of the votes and the entrepreneur belongs to it. Also, since $\sum_{i \in D} v_{i}>\sum_{i \in C} v_{i}, \sum_{i \in D} v_{i}+v_{\pi(I)}>\frac{1}{2}$, and so $D \cup$ $\{\pi(I)\} \in S(\mathbf{v})$.

If the entrepreneur has $\underline{v}$ votes, one just needs to make sure that she is one of the members of coalition $C$. This is always possible because, in case 2), $\Delta_{k}=0$ for $k$ even, and in particular $\Delta_{2}=0$. Therefore, $\underline{v}=v_{\pi(1)}=v_{\pi(2)}$. So, we can have $\pi(2)$ be the entrepreneur. Coalition $C \cup\{\pi(I)\} \in S(\mathbf{v})$ because it has $\frac{1}{2}$ of the votes and the entrepreneur is a member. Also, since $\sum_{i \in D} v_{i}>\sum_{i \in C} v_{i}, \sum_{i \in D} v_{i}+v_{\pi(I)}>\frac{1}{2}$, and so $D \cup\{\pi(I)\} \in S(\mathbf{v})$.

Finally, case 2c) is when all $\Delta$ 's are zero. All shareholder have the same number of votes, $\frac{1}{I}$. The entrepreneur is shareholder $\pi(I)$, and therefore coalitions $C \cup\{\pi(I)\}$ and $D \cup\{\pi(I)\}$ belong to $S(\mathbf{v})$ because they have $\frac{1}{2}$ of the votes and the entrepreneur is a member in both.

Now take $\mathbf{c}^{*}(\boldsymbol{R})$. By Proposition $2, \mathbf{c}^{*}(\mathcal{R})$ is one of the voting distributions that generate $\mathcal{R}$, and so the above statement holds for it. Letting $\pi$ be the permutation 
that "orders" $\mathbf{c}^{*}(\boldsymbol{R})$, we have:

$$
\begin{aligned}
1 & =\sum_{i \in C} c_{i}^{*}(\mathcal{R})+\sum_{i \in D} c_{i}^{*}(\mathcal{R})+c_{\pi(I)}^{*}(\mathcal{R})+c_{\pi(1)}^{*}(\mathcal{R}) \\
& =\left(\sum_{i \in C} c_{i}^{*}(\mathcal{R})+c_{\pi(I)}^{*}(\mathcal{R})\right)+\left(\sum_{i \in D} c_{i}^{*}(\mathcal{R})+c_{\pi(I)}^{*}(\mathcal{R})\right)-\left(c_{\pi(I)}^{*}(\mathcal{R})-c_{\pi(1)}^{*}(\mathcal{R})\right) \\
& \geq 2 \lambda(\mathcal{R})-\left(c_{\pi(I)}^{*}(\mathcal{R})-c_{\pi(1)}^{*}(\mathcal{R})\right)
\end{aligned}
$$

Where the first line uses items 1 ) and 2) of the statement and the third line follows from the fact that, by 3), coalitions $C \cup\{\pi(I)\}$ and $D \cup\{\pi(I)\}$ are strong and hence at the solution $\sum_{i \in C} c_{i}^{*}(\boldsymbol{R})+c_{\pi(I)}^{*}(\mathcal{R}) \geq \lambda(\mathcal{R})$ and $\sum_{i \in D} c_{i}^{*}(\mathcal{R})+c_{\pi(I)}^{*}(\mathcal{R}) \geq \lambda(\mathcal{R})$. Equation (12) follows from the last line and the fact that shareholders $\pi(I)$ and $\pi(1)$ are the ones with the maximum and minimum cash flow respectively. 


\section{References}

[1] Aumann, R., 1959. Acceptable points in general cooperative $n$-person games. In: Kuhn, H.W., Tucker, A.W. (Eds.), Contributions to the Theory of Games IV. Princeton University Press, Princeton.

[2] Bennedsen, M., and Wolfenzon, D., 1999. Inverstor protection in corporations with concentrated ownership. Unpublished working paper. Harvard University.

[3] Berle, A., Means, G., 1932. The Modern Corporation and Private Property. Macmillan, New York.

[4] Burkart, M., Gromb, D., Panunzi, F., 1997. Large shareholders, monitoring, and the value of the firm. Quarterly Journal of Economics 112, 693-728.

[5] Burkart, M., Gromb, D., Panunzi F., 1998. Why higher takeover premia protect minority shareholders. Journal of Political Economy 106, 172-204.

[6] Clark, R., 1986. Corporate Law. Little, Brown and Company, Boston.

[7] Choper, J.H., Coffee, J.H., Gilson, R.J., 1995. Cases and Materials on Corporations. Little, Brown and Company, Boston.

[8] Easterbrook, F.H., Fischel, R.D., 1991, The Economic Structure of Corporate Law, Harvard University Press.

[9] Gomes, A., Novaes, W., 1999. Multiple Large Shareholders in Corporate Governance. Unpublished Working Paper. The Wharton School.

[10] Grossman, S., Hart, O., 1980. Takover bids, the free-rider problem, and the theory of the corporation. Bell Journal of Economics 11, 42-64.

[11] Grossman, S., Hart, O., 1988. One share-one vote and the market for corporate control. Journal of Financial Economics 20, 175-202.

[12] Hamilton, R.W., 1996. The Law of Corporations in a Nutshell. West Publishing Co., St. Paul.

[13] Harris, M., Raviv, A., 1988. Corporate governance: Voting rights and majority rules. Journal of Financial Economics 20, 203-235.

[14] Jensen, M., Meckling W., 1976. Theory of the firm: Managerial behavior, agency costs, and ownership structure. Journal of Financial Economics 3, 305360.

[15] La Porta, R., Lopez-de-Silanes F., Shleifer, A., Vishny, R.W., 1998. Law and Finance. Journal of Political Economy 106, 1113-1155.

[16] La Porta, R., Lopez-de-Silanes F., Shleifer, A., 1999. Corporate ownership around the world. Journal of Finance 54, 471-517. 
[17] Levy vs. Markal Sales Corporation. 268 Ill.App.3d 455, 643 N.E.2d 1206, 205 Ill.Dec. 599.

[18] O'Neals, F.H., 1987. Oppresion of minority shareholders: protecting minority rights. Close Corporations Law Symposium, Cleveland State Law Review.

[19] Pagano, M., Roel A., 1998. The choice of stock ownership structure: Agency costs, monitoring, and the decision to go Public. Quarterly Journal of Economics 113, 187-225.

[20] Shleifer, A., Vishny, R., 1986. Large shareholders and corporate control. Journal of Political Economy 94, 461-488.

[21] Shleifer, A., Vishny, R., 1997. A survey of corporate governance. Journal of Finance 52, 737-783.

[22] U.S. Bureau of the Census, 1993. Statistical Abstract of the U.S. 531.

[23] Zwiebel, J., 1995. Block investment and partial benefits of corporate control. Review of Economic Studies 62, 161-185. 